\title{
Lipid profile and glucose changes after supplementation with astaxanthin: a systematic review and meta-analysis of randomized controlled trials
}

\author{
Sorin Ursoniu ${ }^{1}$, Amirhossein Sahebkar², Maria-Corina Serban ${ }^{3}$, Maciej Banach ${ }^{4}$
}

\begin{abstract}
${ }^{1}$ Department of Functional Sciences, Discipline of Public Health, Victor Babes University of Medicine and Pharmacy Timisoara, Timișoara, Romania ${ }^{2}$ Biotechnology Research Center, Mashhad University of Medical Sciences, Mashhad, Iran ${ }^{3}$ Department of Functional Sciences, Discipline of Pathophysiology, Victor Babes University of Medicine and Pharmacy Timisoara, Timișoara, Romania ${ }^{4}$ Department of Hypertension, Chair of Nephrology and Hypertension, Medical University of Lodz, Lodz, Poland
\end{abstract}

Submitted: 18 January 2015

Accepted: 18 January 2015

Arch Med Sci 2015; 11, 2: 253-266

DOI: $10.5114 /$ aoms.2015.50960

Copyright $\odot 2015$ Termedia \& Banach

\section{Abstract}

Introduction: Many studies have shown that oral supplementation with astaxanthin may be a novel potential treatment for inflammation and oxidative stress in cardiovascular diseases, but evidence of the effects on lipid profile and glucose is still inconclusive. Therefore, we performed a meta-analysis to evaluate the efficacy of astaxanthin supplementation on plasma lipid and glucose concentrations.

Material and methods: The search included PubMed, Cochrane Library, Scopus, and EMBASE (up to November 27, 2014) to identify randomized controlled trials (RCTs) investigating the effects of astaxanthin supplementation on lipid profile and glucose levels. Two independent reviewers extracted data on study characteristics, methods and outcomes.

Results: Seven studies meeting inclusion criteria with 280 participants were selected for this meta-analysis; 163 participants were allocated to the astaxanthin supplementation group and 117 to the control group. A random-effect meta-analysis of data from 7 RCTs (10 treatment arms) did not show any significant effect of supplementation with astaxanthin on plasma concentrations of total cholesterol (weighted mean difference (WMD): $-1.52 \mathrm{mg} / \mathrm{dl}, 95 \% \mathrm{Cl}$ : -8.69 to $-5.66, p=0.679)$, LDL-C (WMD: $+1.25 \mathrm{mg} / \mathrm{dl}, 95 \% \mathrm{Cl}:-6.70$ to +9.21 , $p=0.758)$, HDL-C (WMD: $+1.75 \mathrm{mg} / \mathrm{dl}, 95 \% \mathrm{Cl}:-0.92$ to $+4.42, p=0.199$ ), triglycerides (WMD: $-4.76 \mathrm{mg} / \mathrm{dl}, 95 \% \mathrm{Cl}:-21.52$ to $+12.00, p=0.578)$, or glucose (WMD: $-2.65 \mathrm{mg} / \mathrm{dl}, 95 \% \mathrm{Cl}:-5.84$ to $+0.54, p=0.103$ ). All these effect sizes were robust, and omission of any of the included studies did not significantly change the overall estimate.

Conclusions: This meta-analysis of data from 10 RCT arms did not indicate a significant effect of supplementation with astaxanthin on plasma lipid profile, but a slight glucose-lowering effect was observed. Further, well-designed trials are necessary to validate these results.

Key words: astaxanthin, lipids, antioxidants, glucose.

\section{Introduction}

Astaxanthin (ASTX) is a lipophilic, pinkish-orange carotenoid (3,3'-dihydroxy- $\beta, \beta$-carotene- 4,4 '-dione) found in algae, seafood (crustacean

\author{
Corresponding author: \\ Maria-Corina Serban PhD \\ Victor Babes University \\ of Medicine and Pharmacy \\ Timisoara \\ Str. Daliei Nr. 2 \\ Bl. D4, Sc. B, Ap.06 \\ 300558 Timisoara, Romania \\ Phone: 0040752444900 \\ E-mail:dr.corinaserban@ \\ yahoo.com
}


shells, crab, shrimps, fish) and various plants, giving them their exclusive colored aspect [1]. Presently, the main source of ASTX is the microalga Haematococcus pluvialis, containing the maximum concentrations [2]. Astaxanthin is also used as a dietary additive in the USA, Japan, South Korea and Sweden [3]. Like other carotenoids, ASTX manifests high protective antioxidant $[4,5]$ and anticancer [6-8] properties, reduces oxidative stress and inflammation [9-11], reduces rethrombosis after thrombolysis [12] and is efficient in ischemia-reperfusion [13, 14], arterial hypertension [15, 16] and dyslipidemia [15, 17]. Astaxanthin is considered the most powerful natural carotenoid antioxidant, being 65 times more potent than vitamin C, 54 times more than $\beta$-carotene, 14 times more than vitamin $\mathrm{E}$, and 10 times more powerful than zeaxanthin, lutein and canthaxanthin $[18,19]$. However, the powerful antioxidant capacity of ASTX is at least moderately caused by its distinctive chemical structure, its polar ends interacting with phospholipid head groups or water in the aqueous condition, suppressing radicals from the surface or inside the lipid bilayer [20]. Moreover, cis-ASTX usually accumulates in blood plasma compared with the trans form, as a consequence of evident smaller chain lengths [21].

In an in vitro membrane model, ASTX preserved the membrane consistency and successfully inhibited the formation of lipid peroxide, in contrast to lutein and $\beta$-carotene, which damaged the structure of the membrane and raised lipid hydroperoxide levels [22]. Moreover, ASTX reduces cellular lipid accumulation in lipid-loaded hepatocytes by acting as a peroxisome proliferator-activated receptor $\alpha$ (PPAR- $\alpha)$ agonist and PPAR- $\gamma$ antagonist [23]. An experimental study proved that ASTX consumes increased peroxisome proliferator-activated receptor- $\gamma$ coactivator $1-\alpha(P G C-1 \alpha)$ in skeletal muscle, leading to acceleration of lipid usage, as a result of initialization of mitochondrial aerobic metabolism [24]. Furthermore, it has been shown that ASTX is more efficient than many antioxidants for decreasing liver weight and abdominal fat-pad weight in obese mice [25].

The evidence of the effects of ASTX on lipid profile and glucose are based on relatively small sample sizes and are still inconclusive. Therefore, a meta-analysis was performed to evaluate the efficacy of ASTX supplementation on plasma lipid and glucose concentrations.

\section{Material and methods}

\section{Search strategy}

This study was designed according to the guidelines of the 2009 preferred reporting items for systematic reviews and meta-analysis (PRISMA) statement [1]. SCOPUS (http://www.scopus.com) and
Medline (http://www.ncbi.nlm.nih.gov/pubmed) databases were searched using the following search terms in titles and abstracts (also in combination with MESH terms): ("randomized controlled trial" or randomized or placebo or cholesterol or triglyceride or LDL or LDL-C or LDL-cholesterol or HDL or HDL-C or HDL-cholesterol or hyperlipidemia or hyperlipidemic or hypolipidemic or dyslipidemia or dyslipidemic) and (astaxanthin). The wild-card term "*” was used to increase the sensitivity of the search strategy. No language restriction was used in the literature search. The search was limited to studies in humans. The literature was searched from inception to November 27, 2014.

\section{Study selection}

Original studies were included if they met the following inclusion criteria: (i) a randomized clinical case-control or case-crossover trial, (ii) investigated the impact of ASTX on plasma/serum concentrations of at least one of the main lipid parameters (i.e. total cholesterol, low-density lipoprotein cholesterol (LDL-C), high-density lipoprotein cholesterol (HDL-C) or triglycerides), (iii) presentation of sufficient information on plasma/ serum lipid levels at baseline and at the end of the study in both ASTX and control groups, and (iv) administering ASTX for a period of at least 2 weeks. Exclusion criteria were (i) non-clinical studies, (ii) uncontrolled trials, (iii) using non-standardized preparations containing ASTX, and (iv) lack of sufficient information on baseline or follow-up lipid concentrations. Exclusion of an article for the latter reason was applied if no feedback was received after contacting the author(s).

\section{Data extraction}

Eligible studies were reviewed and the following data were abstracted: 1) first author's name; 2) year of publication; 3) study location; 4) number of participants in the spirulina and control groups; 5) age, gender and body mass index (BMI) of study participants; 6) circulating concentrations of total cholesterol, LDL-C, HDL-C, triglycerides and glucose; 7) systolic and diastolic blood pressures; 8) homeostasis model assessment-estimated insulin resistance (HOMA-IR) index; and 9) prevalence of smoking, type 2 diabetes, dyslipidemia, hypertension and coronary heart disease (CHD).

\section{Quality assessment}

A systematic assessment of bias in the included studies was performed using the Cochrane criteria [26]. The items used for the assessment of each study were as follows: adequacy of sequence generation, allocation concealment, blinding, address ing dropouts (incomplete outcome data), selective 
outcome reporting, and other potential sources of bias. According to the recommendations of the Cochrane Handbook, a judgment of "yes" indicated low risk of bias, while "no" indicated high risk of bias. Labeling an item as "unclear" indicated an unclear or unknown risk of bias.

\section{Quantitative data synthesis}

A meta-analysis was conducted using the Comprehensive Meta-Analysis (CMA) V2 software (Biostat, NJ) [27]. Plasma lipid (total cholesterol, LDL-C, HDL-C and triglycerides) and glucose concentrations were collated in $\mathrm{mg} / \mathrm{dl}$. Multiplication by 38.6 and 88.5 was used to convert cholesterol (total cholesterol, HDL-C or LDL-C) and triglyceride, respectively, expressed in $\mathrm{mmol} / \mathrm{l}$ into $\mathrm{mg} / \mathrm{dl}$. Standard deviations (SDs) of the mean difference were calculated using the following formula: $S D=$ square root $\left[\left(\mathrm{SD}_{\text {pre-treatment }}\right)^{2}+\left(\mathrm{SD}_{\text {post-treatment }}\right)^{2}-(2 \mathrm{R} \times\right.$ $\left.\left.\mathrm{SD}_{\text {pre-treatment }} \times \mathrm{SD}_{\text {post-treatment }}^{\text {pre-treatment }}\right)\right]$, assuming a correlation coefficient $(R)=0.5$. In case of reporting SEM, SD was estimated using the following formula: $\mathrm{SD}=$ SEM $\times$ sqrt $(n)$, where $n$ is the number of subjects.

Net changes in measurements (change scores) were calculated for parallel and crossover trials, as follows: (measure at end of follow-up in the treatment group - measure at baseline in the treatment group) - (measure at end of follow-up in the control group - measure at baseline in the control group). A random-effects model and the generic inverse variance method were used to compensate for the heterogeneity of studies in terms of study design, ASTX dose and demographic characteristics (e.g. age, gender, underlying disease and comorbidities) of populations studied. In order to avoid double counting of subjects and consequent unit-of-analysis error in the trials with more than 1 treatment arm, the control group was evenly (where possible) split. Effect size was expressed as weighted mean difference (WMD) and 95\% confidence interval $(\mathrm{Cl})$. In order to evaluate the influence of each study on the overall effect size, sensitivity analysis was conducted using the onestudy remove (leave-one-out) approach [28, 29].

\section{Meta-regression}

Random-effects meta-regression was performed using the unrestricted maximum likelihood method to evaluate the association between calculated WMD in plasma lipids and glucose concentrations with ASTX dose in individual studies.

\section{Publication bias}

Potential publication bias was explored using visual inspection of Begg's funnel plot asymmetry, and Begg's rank correlation and Egger's weighted regression tests. Duval \& Tweedie's "trim and fill" method was used to adjust the analysis for the effects of publication bias [30].

\section{Results}

\section{Search results and trial flow}

The initial screening for potential relevance removed articles whose titles and/or abstracts were obviously irrelevant. Among the 26 full text articles assessed for eligibility, 19 studies were excluded: 15 because of not assessing lipid parameters, 2 because of not having a controlled design, and 2 because of not having a randomized design (Figure 1). After final assessment, 7 randomized con-

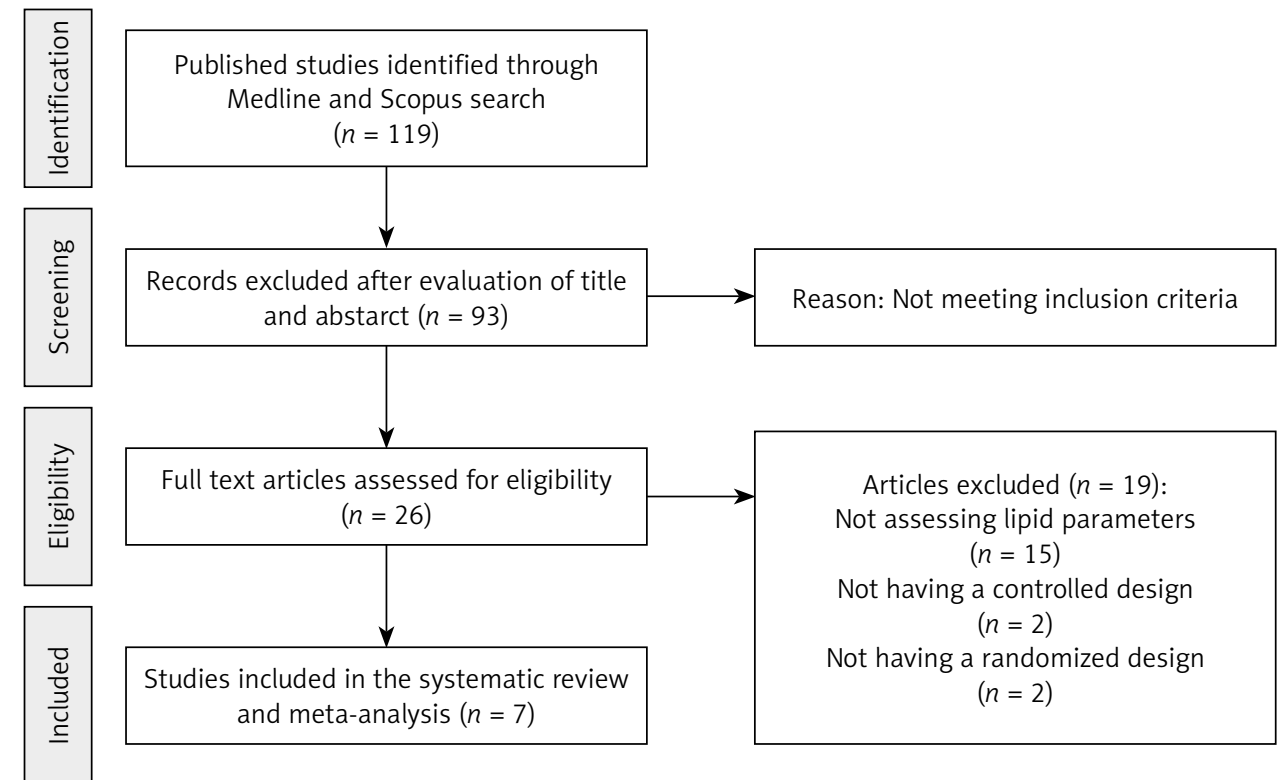

Figure 1. Flow diagram of the study selection procedure showing the number of eligible randomized controlled trials for the meta-analysis of the impact of astaxanthin supplementation on plasma lipid concentrations 
trolled trials (RCTs) fulfilled the inclusion criteria and were preferred for the final meta-analysis. In total, 280 participants were randomized, of whom 163 were allocated to the ASTX supplementation group and 117 to the control group in the selected studies. The number of participants in these trials ranged from 20 to 63 . Included studies were published between 2007 and 2013, and were conducted in Serbia, South Korea, Finland, Canada and Japan (3 trials). Doses ranging from $4 \mathrm{mg}$ to $20 \mathrm{mg}$ ASTX/day were administered in the included trials. Duration of supplementation with ASTX ranged from 4 weeks to 3 months. All 7 trials were designed as parallel-group studies, comprising a total of 10 treatment arms. Demographic and baseline parameters of the included studies are shown in Table I. The risk of bias of the included trials according to Cochrane quality assessment tool is shown in Figure 2.

\section{Quantitative data synthesis}

The random-effect meta-analysis of data from 7 RCTs (10 treatment arms) did not show any significant effect of supplementation with ASTX on plasma concentrations of total cholesterol (WMD: $-1.52 \mathrm{mg} / \mathrm{dl}, 95 \% \mathrm{Cl}:-8.69$ to $-5.66, p=$ 0.679 ) (Figure 2), LDL-C (WMD: $+1.25 \mathrm{mg} / \mathrm{dl}$, $95 \% \mathrm{Cl}:-6.70$ to $+9.21, p=0.758$ ) (Figure 3), HDL-C (WMD: $+1.75 \mathrm{mg} / \mathrm{dl}, 95 \% \mathrm{Cl}:-0.92$ to $+4.42, p=$ 0.199 ) (Figure 4), triglycerides (WMD: $-4.76 \mathrm{mg} / \mathrm{dl}$, 95\% Cl: -21.52 to $+12.00, p=0.578$ ) (Figure 5), and glucose (WMD: $-2.65 \mathrm{mg} / \mathrm{dl}, 95 \% \mathrm{Cl}:-5.84$ to $+0.54, p=0.103$ ) (Figure 6). All these effect sizes were robust, and omission of any of the included studies did not significantly change the overall estimate (Figures 2-7).

\section{Meta-regression analysis}

Since different doses of ASTX were used among the included trials, a meta-regression analysis was conducted to evaluate the association between changes in plasma lipids and glucose concentrations and ASTX dose as a potential moderator variable. The results of the meta-regression did not suggest any significant dose-response association for the impact of ASTX on evaluated parameters, i.e. total cholesterol (slope: $-0.44 ; 95 \% \mathrm{Cl}$ : -2.80 to $+1.91 ; p=0.712$ ), LDL-C (slope: -0.054 ; $95 \% \mathrm{Cl}:-1.45$ to $+1.34 ; p=0.940)$, HDL-C (slope: $+0.119 ; 95 \% \mathrm{Cl}:-0.34$ to $+0.58 ; p=0.609$ ), triglycerides (slope: $-2.50 ; 95 \% \mathrm{Cl}:-4.74$ to -0.25 ; $p=0.029$ ) and glucose (slope: $-0.19 ; 95 \% \mathrm{Cl}$ : -1.19 to $+0.80 ; p=0.701$ ) (Figure 8).

\section{Publication bias}

Visual inspection of the funnel plot of the study precision (inverse SEM) by effect size (mean dif- ference) suggested asymmetry for the impact of ASTX on total cholesterol, LDL-C, HDL-C and glucose. Using the trim-and-fill method, 3, 4, 1 and 3 potentially missing studies were imputed for the analysis of total cholesterol, LDL-C, HDL-C and glucose, respectively. The imputed effect size of ASTX on plasma levels of total cholesterol (WMD: -3.32 $\mathrm{mg} / \mathrm{dl}, 95 \% \mathrm{Cl}:-8.70$ to +5.66$)$, LDL-C (WMD: $-2.32 \mathrm{mg} / \mathrm{dl}, 95 \% \mathrm{Cl}:-9.08$ to +4.45$)$, and HDL-C (WMD: $+1.85 \mathrm{mg} / \mathrm{dl}, 95 \% \mathrm{Cl}:-0.79$ to +4.49 ) was not significant, but a slight glucose-lowering effect was observed following imputation (WMD: $-4.01 \mathrm{mg} / \mathrm{dl}, 95 \% \mathrm{Cl}:-6.78$ to -1.25$)$. As for plasma triglyceride concentrations, there was no sign of asymmetry in the funnel plot (Figure 9).

In addition to visual inspection of funnel plots, presence of publication bias was explored using Begg's rank correlation test and Egger's linear regression test. None of these tests indicated evidence of publication bias for the impact of ASTX on the evaluated parameters, apart from significant evidence of bias for the effects of ASTX on plasma glucose levels according to Egger's test (Table II).

\section{Discussion}

To our knowledge, the present systematic review and meta-analysis is the first to assess the effects of ASTX supplementation on lipid profile and glucose concentrations and provides a thorough synthesis of results from RCTs. In contrast to the findings from some studies [31, 32], no significant effect of supplementation with ASTX on plasma lipid profile, but a slight glucose-lowering effect was observed. This effect size was robust in sensitivity analysis, and omission of each individual study did not have a significant effect.

Astaxanthin improved lipid metabolism in a few experimental and human studies [33]. It was speculated that the underlying molecular mechanisms for the supposed hypolipidemic effect of ASTX may be modulated by peroxisome proliferator-activated receptors (PPARs). A recent study investigated the effects of ASTX on key molecules in cholesterol efflux from macrophages, such as ATP-binding cassette transporters (ABC) $A 1$ and $G 1$. The study revealed that ASTX did not modify PPAR- $\gamma$, liver $X$ receptor (LXR) $\alpha$ and $L X R \beta$ levels, but increased the expression of ATP-binding cassette transporter $A 1 / G 1$ and the efflux of cholesterol from macrophages [34]. Another study showed that ASTX increases the levels of apoA1and HDL-mediated macrophage cholesterol efflux via upregulation of expression of ABCA1 and ABCG1 [34]. Since ASTX is a PPAR- $\alpha$ agonist and PPAR- $\gamma$ antagonist, it has been shown to be able to reduce hepatic lipid deposits by rewiring the 


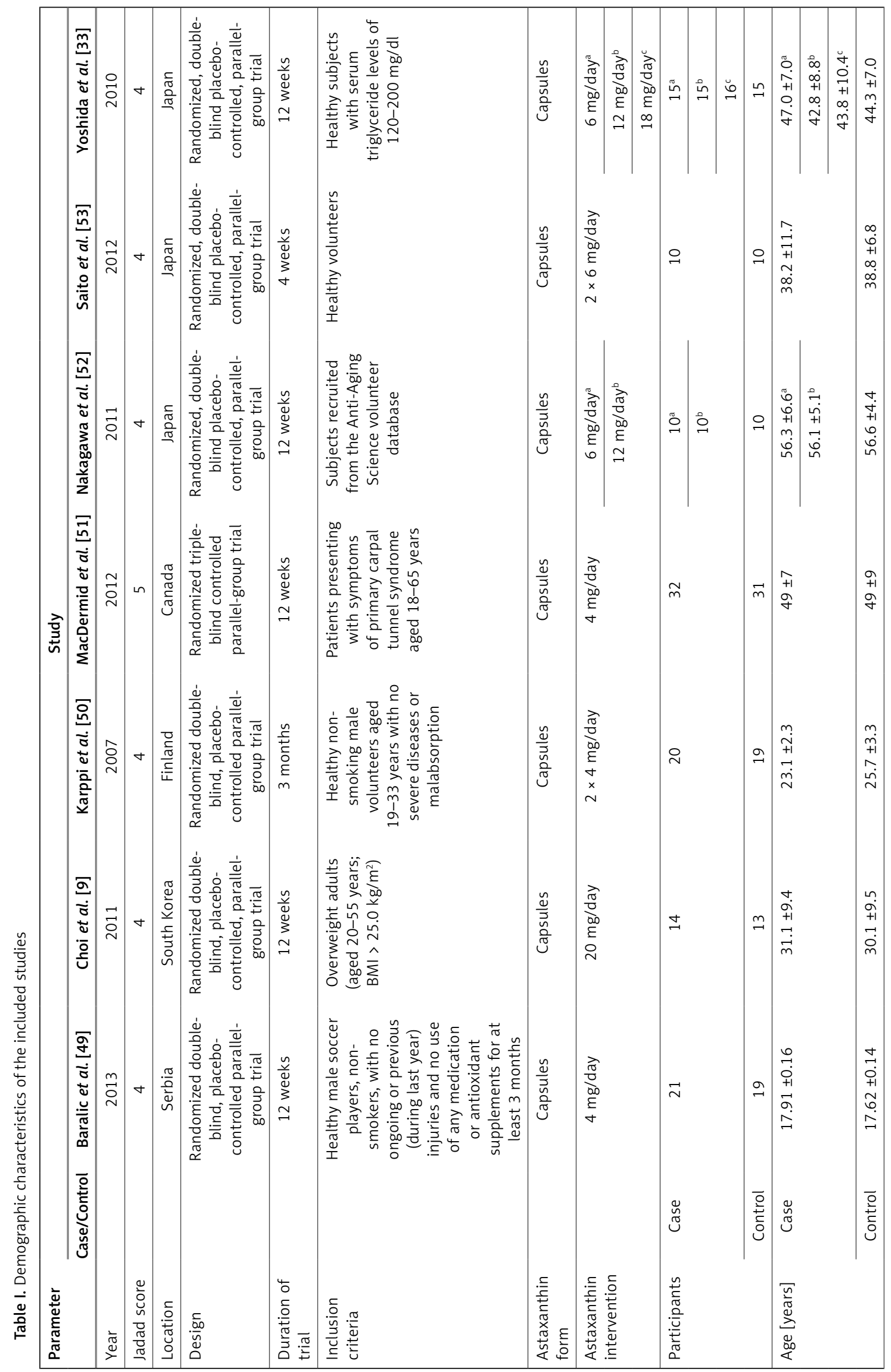




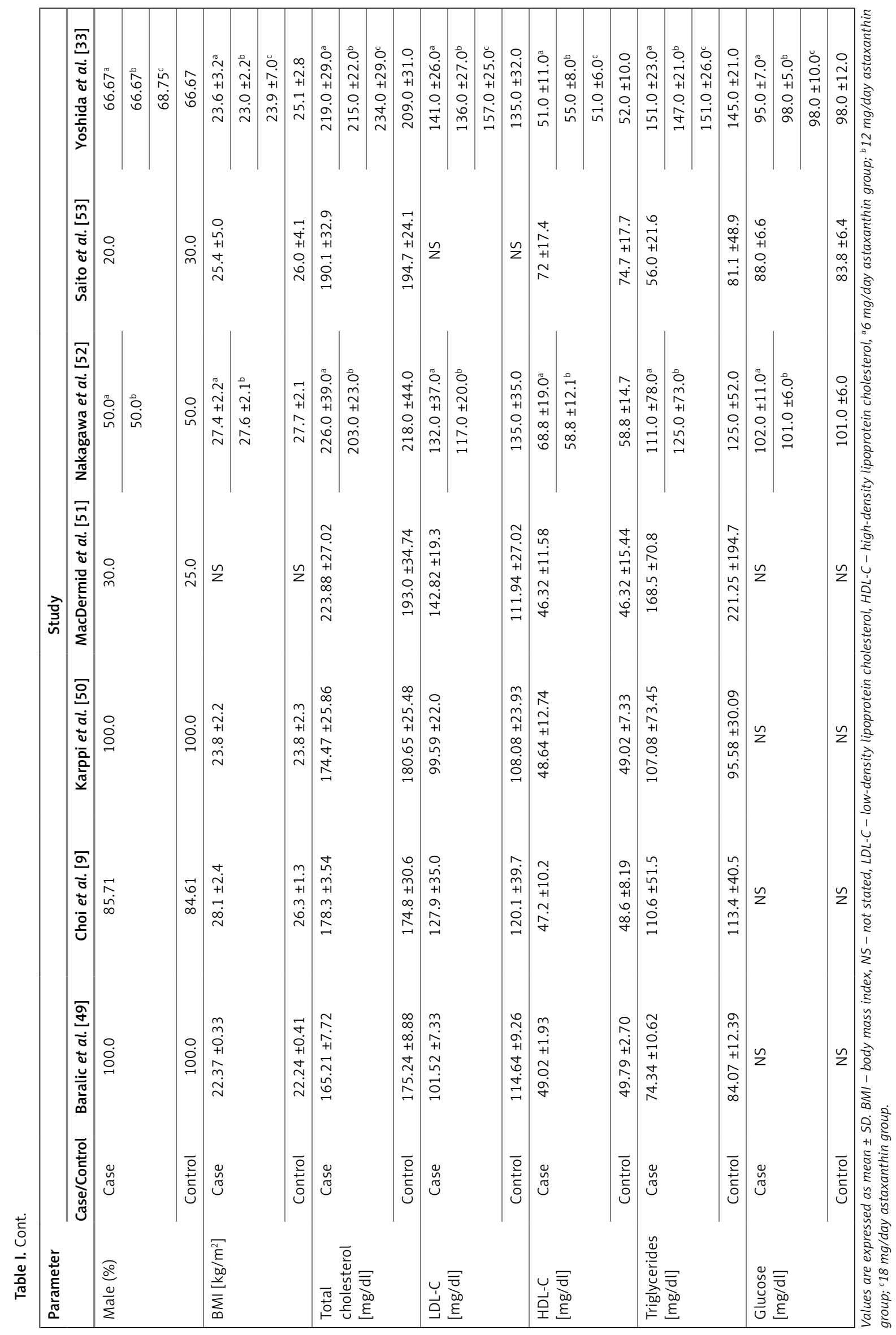




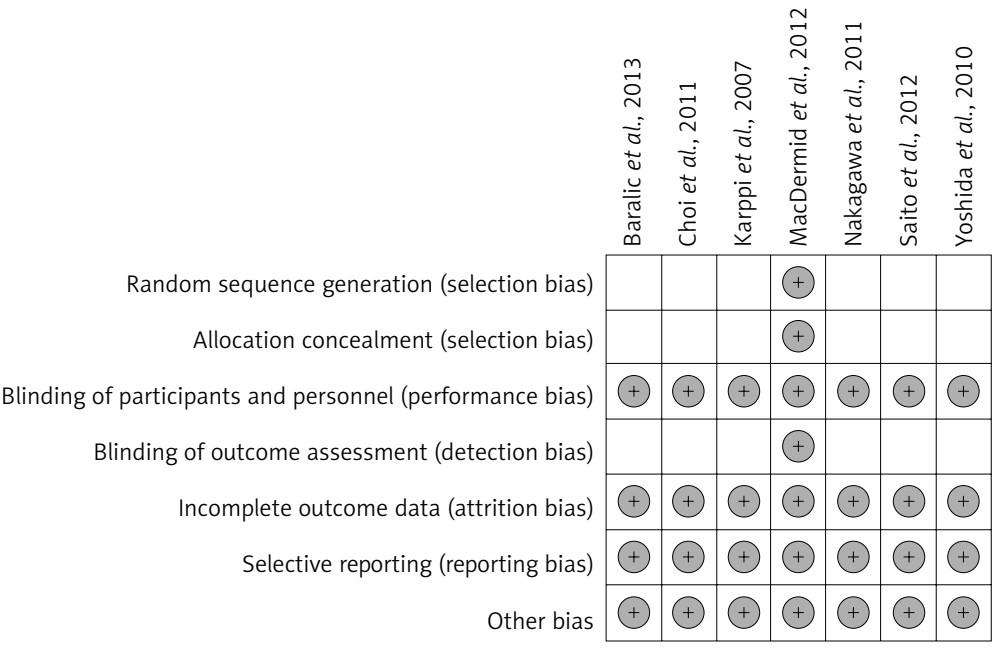

Random sequence generation (selection bias)

Allocation concealment (selection bias)

Blinding of participants and personnel (performance bias)

Blinding of outcome assessment (detection bias)

Incomplete outcome data (attrition bias)

Selective reporting (reporting bias)

Other bias

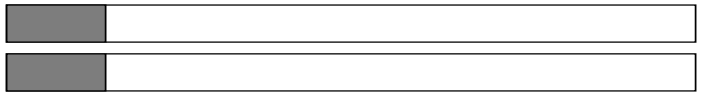

-

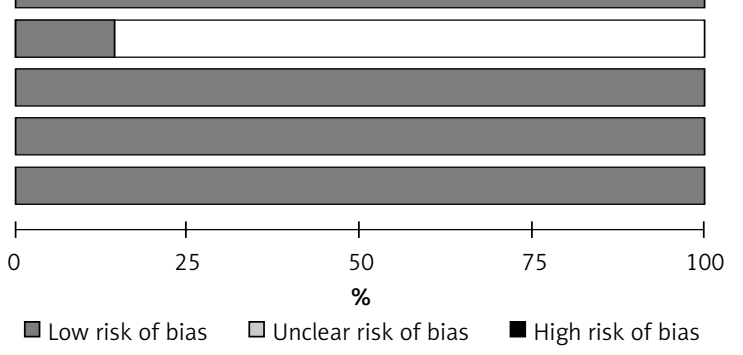

Figure 2. Plots showing the risk of bias of the included trials according to Cochrane quality assessment tool

\section{Study name}

Statistics for each study

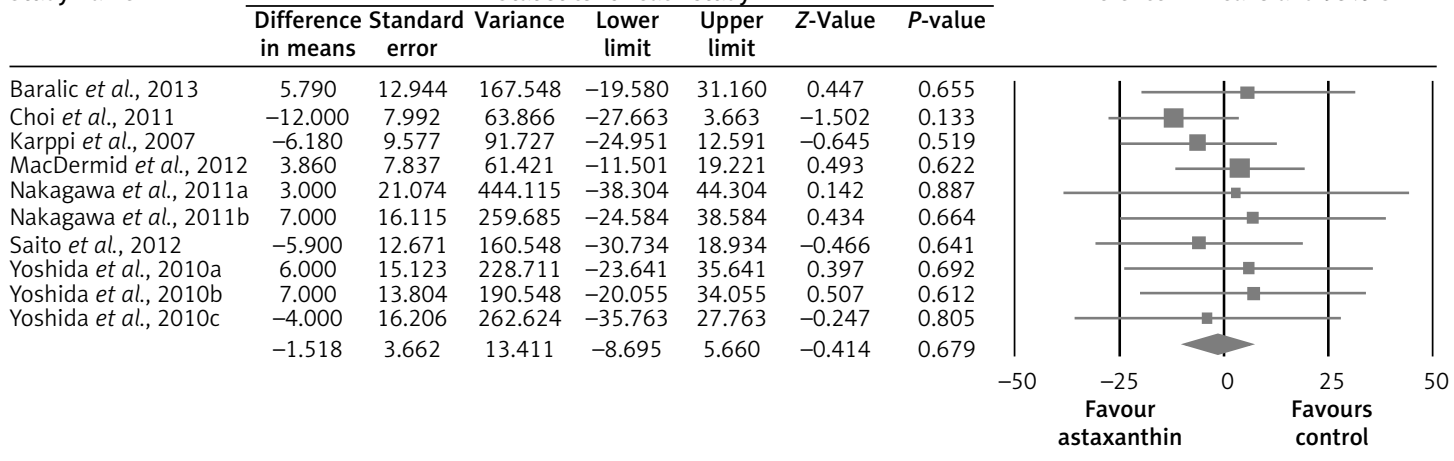

Study name Statistics with study removed

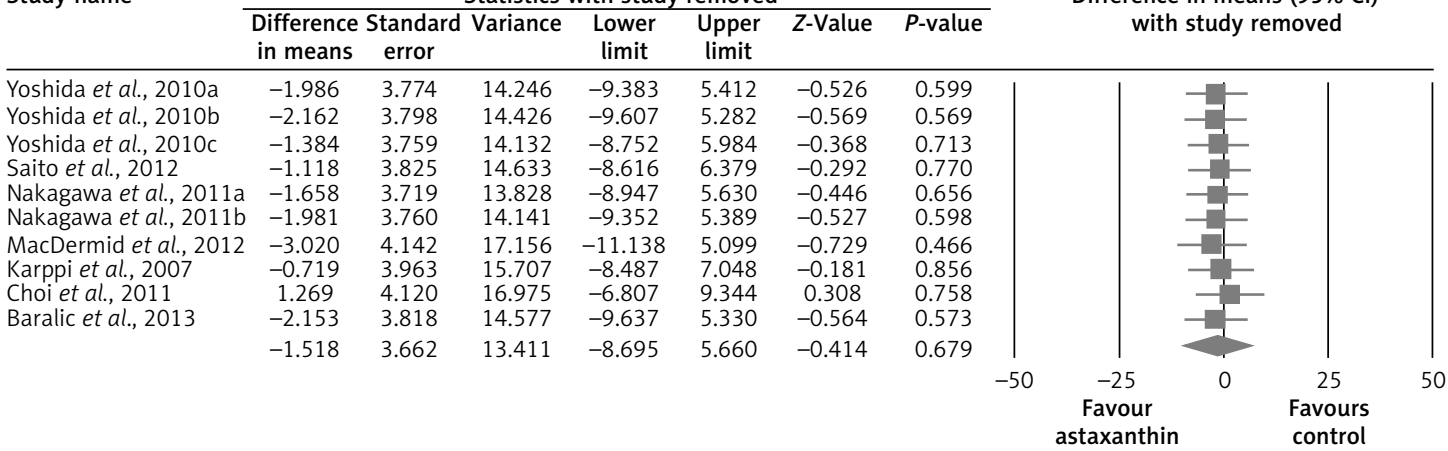

Figure 3. Forest plot detailing weighted mean difference and $95 \%$ confidence intervals for the impact of astaxanthin supplementation on plasma total cholesterol concentrations (upper graph). Leave-one-out sensitivity analysis is shown in the lower graph 


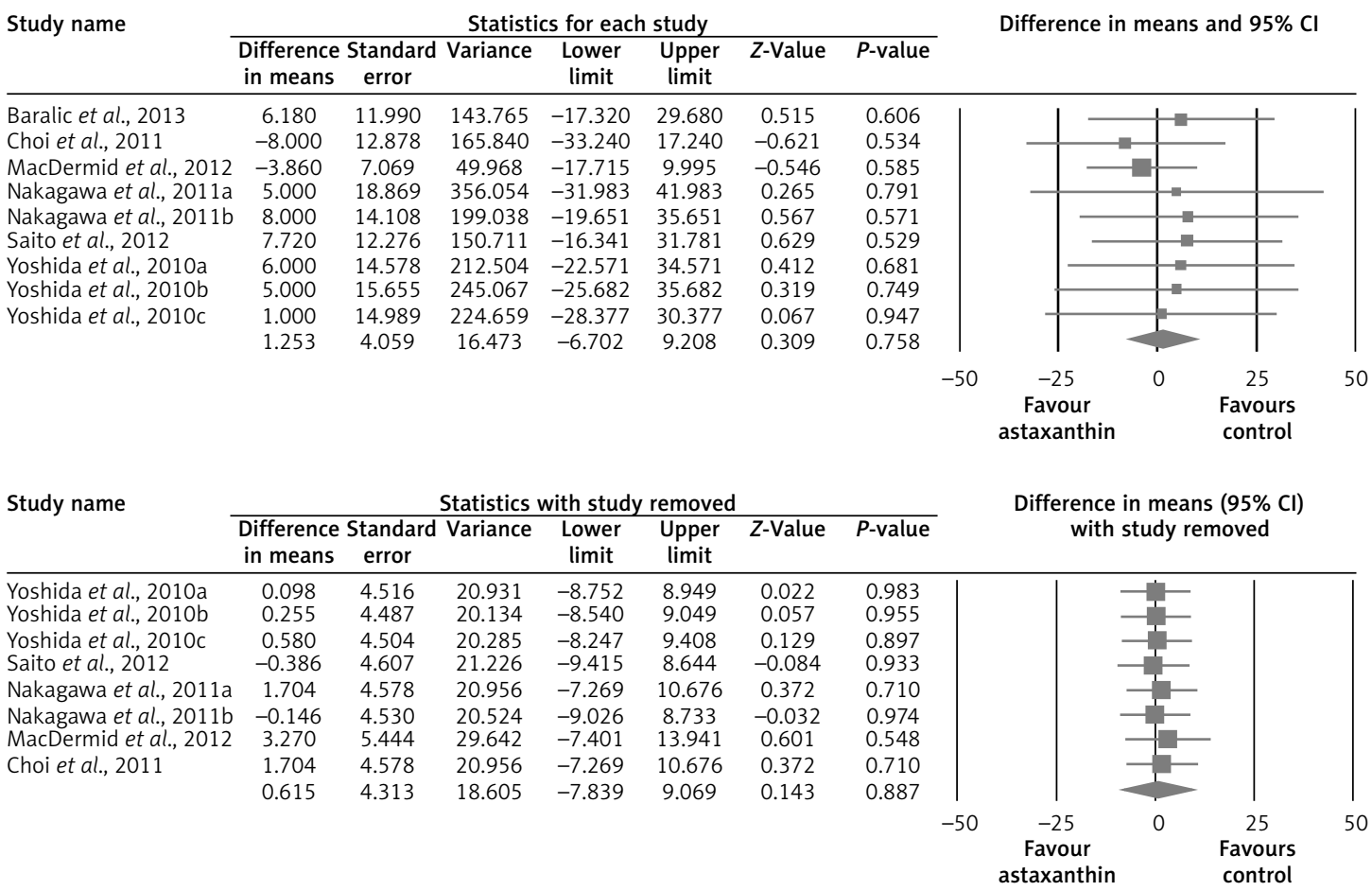

Figure 4. Forest plot detailing weighted mean difference and $95 \%$ confidence intervals for the impact of astaxanthin supplementation on plasma LDL-C concentrations. Leave-one-out sensitivity analysis is shown in the lower graph

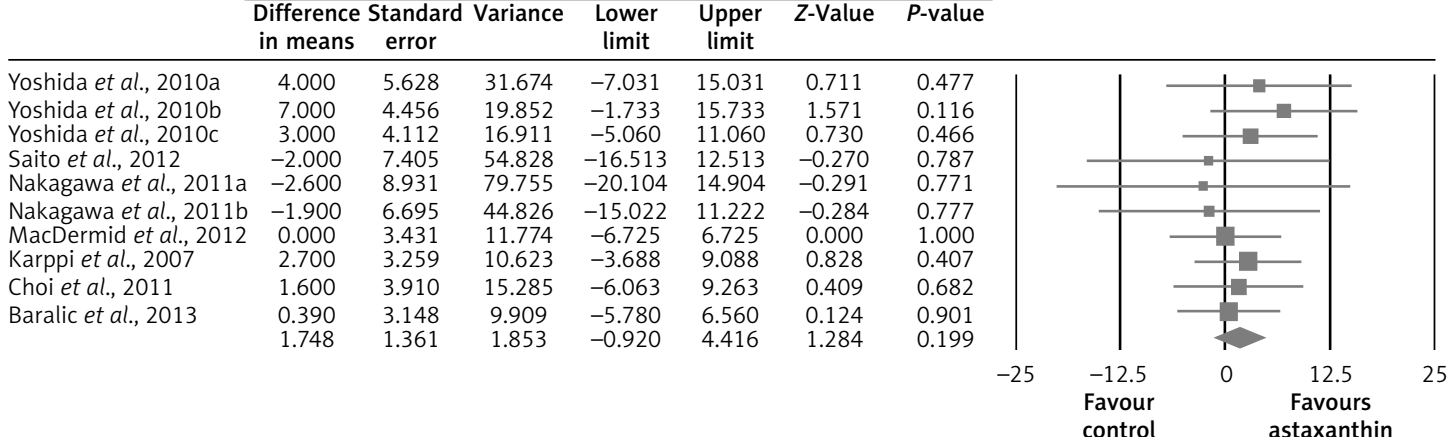

Study name

Statistics with study removed Difference Standard Variance Lower Upper in means error

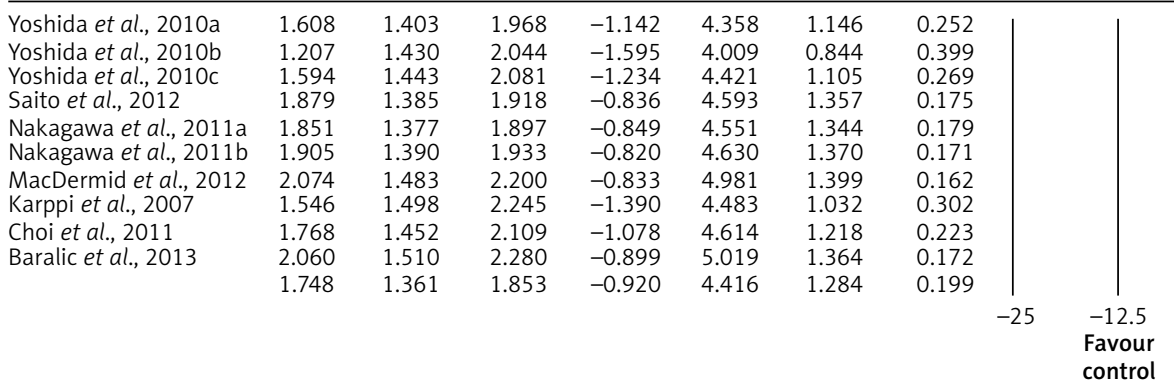

Difference in means $(95 \% \mathrm{Cl})$ with study removed

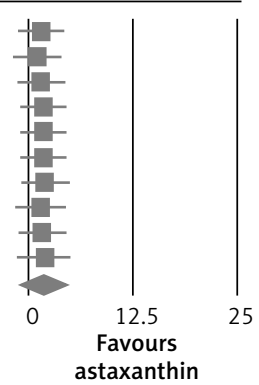

Figure 5. Forest plot detailing weighted mean difference and $95 \%$ confidence intervals for the impact of astaxanthin supplementation on plasma HDL-C concentrations. Leave-one-out sensitivity analysis is shown in the lower graph 


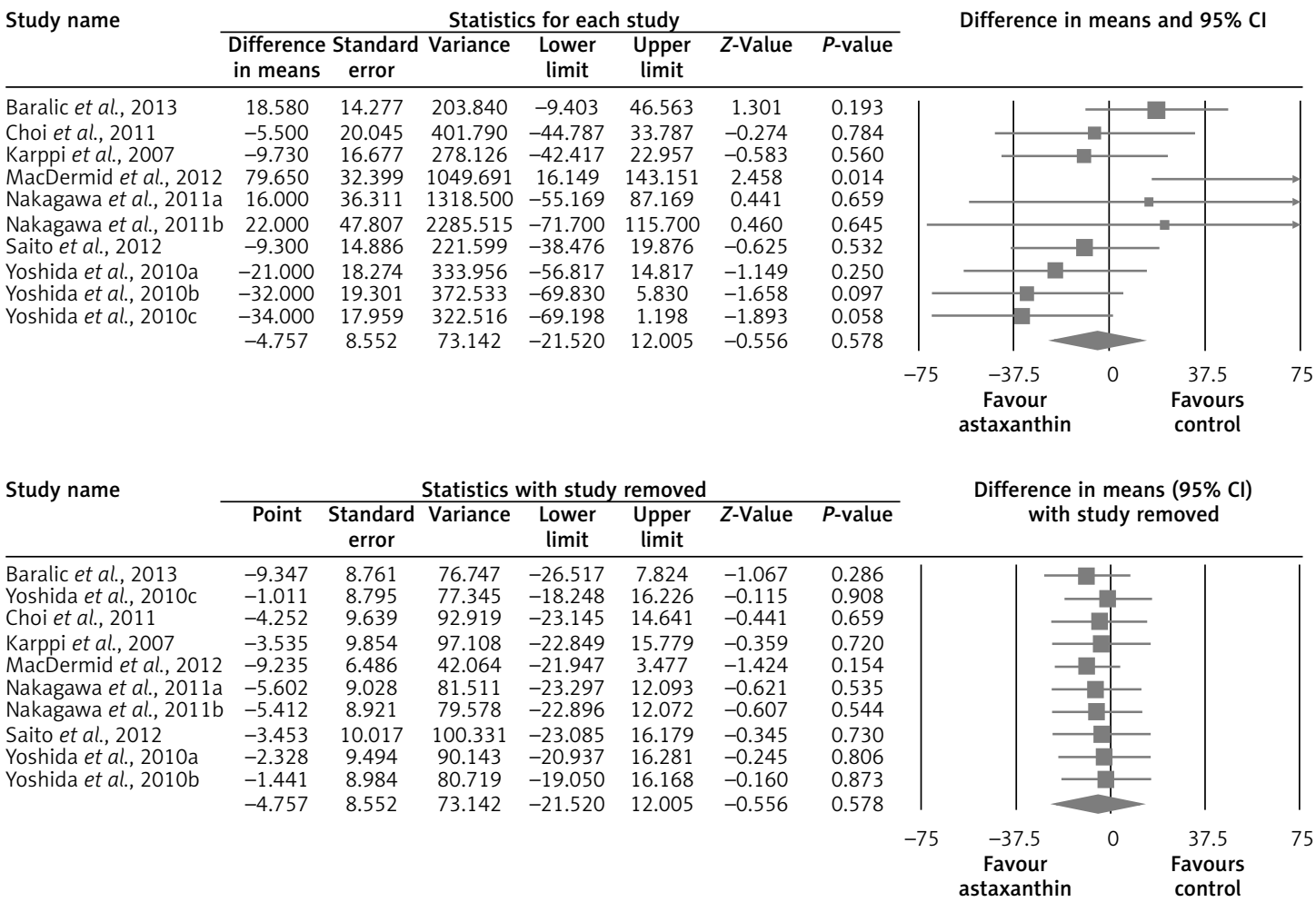

Figure 6. Forest plot detailing weighted mean difference and $95 \%$ confidence intervals for the impact of astaxanthin supplementation on plasma triglyceride concentrations. Leave-one-out sensitivity analysis is shown in the lower graph

Study name

Statistics for each study

Difference in means and $95 \% \mathrm{Cl}$

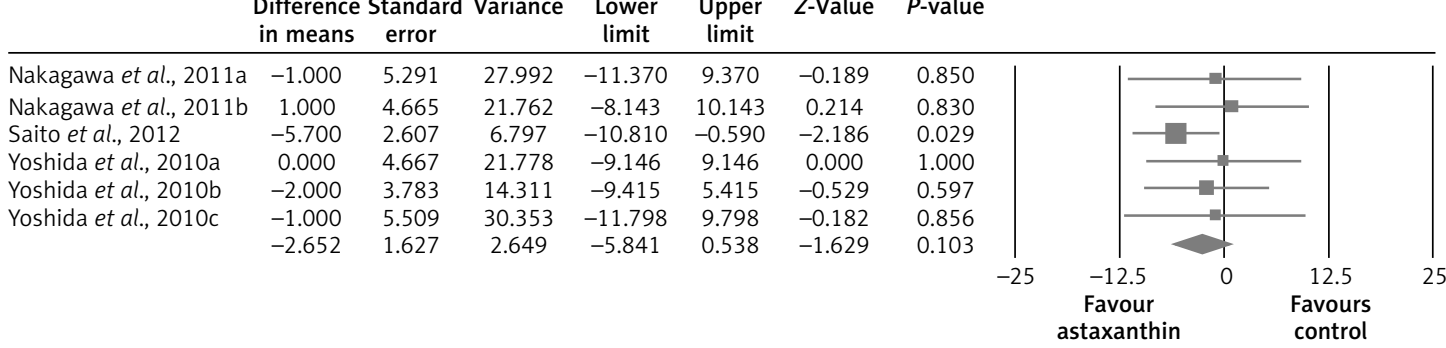

Study name

Statistics with study removed

Difference in means $(95 \% \mathrm{Cl})$ Difference Standard Variance Lower Upper Z-Value $P$-value $\quad$ with study removed

\begin{tabular}{llllllll}
\hline Nakagawa et al., 2011a & -2.824 & 1.710 & 2.926 & -6.177 & 0.528 & -1.651 & 0.099
\end{tabular}

$\begin{array}{llllllll}\text { Nakagawa et al., 2011b } & -3.158 & 1.737 & 3.016 & -6.561 & 0.246 & -1.818 & 0.069\end{array}$

$\begin{array}{llllllll}\text { Saito et al., } 2012 & -0.705 & 2.083 & 4.340 & -4.788 & 3.378 & -0.338 & 0.735\end{array}$

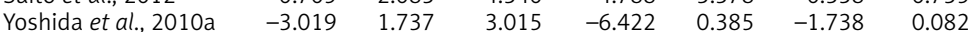

$\begin{array}{llllllll}\text { Yoshida et al., 2010b } & -2.800 & 1.803 & 3.250 & -6.333 & 0.734 & -1.553 & 0.120\end{array}$

$\begin{array}{llllllll}\text { Yoshida et al., 2010c } & -2.809 & 1.704 & 2.902 & -6.148 & 0.529 & -1.649 & 0.099\end{array}$

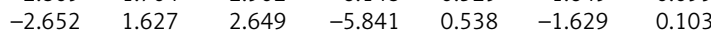

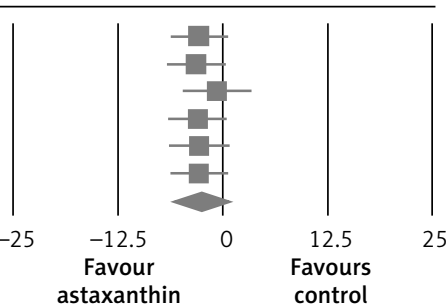

Figure 7. Forest plot detailing weighted mean difference and $95 \%$ confidence intervals for the impact of astaxanthin supplementation on plasma glucose concentrations. Leave-one-out sensitivity analysis is shown in the lower graph 

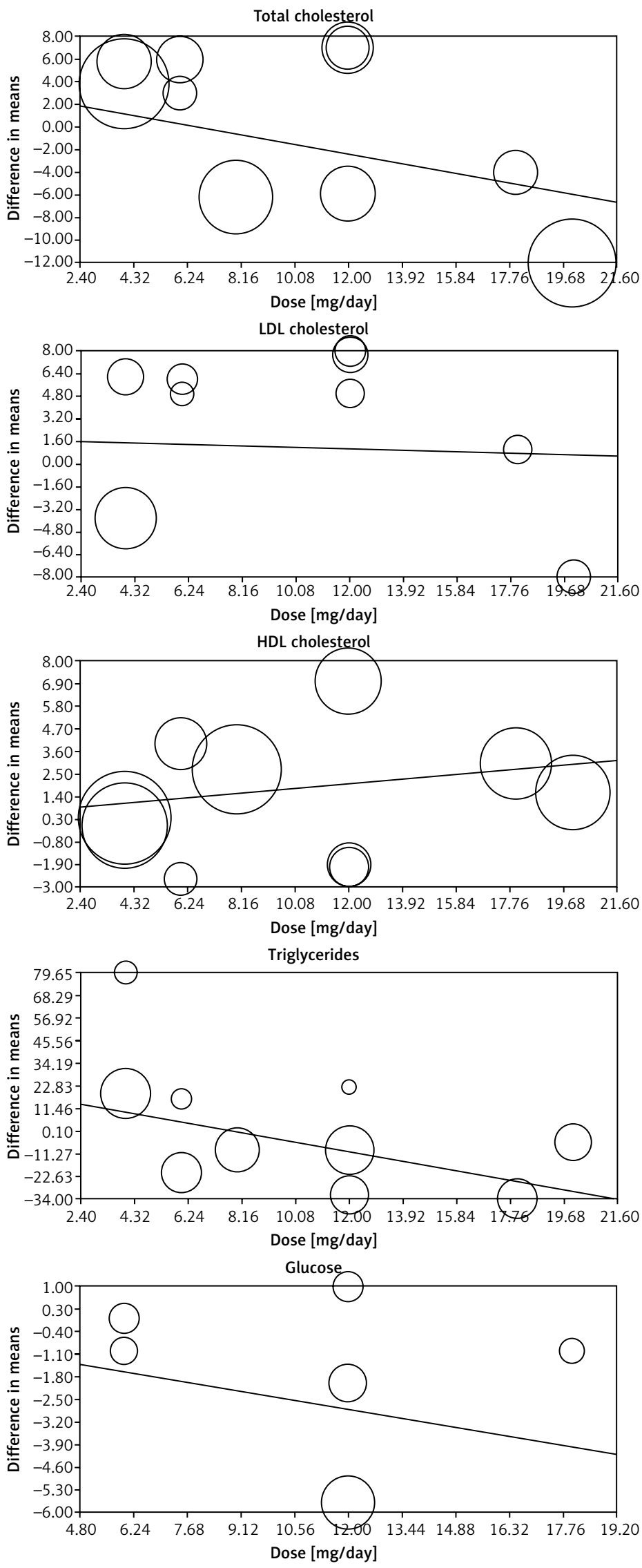

Figure 8. Meta-regression plots of the association between mean changes in plasma lipids and glucose concentrations and administered astaxanthin dose. The size of each circle is inversely proportional to the variance of change 

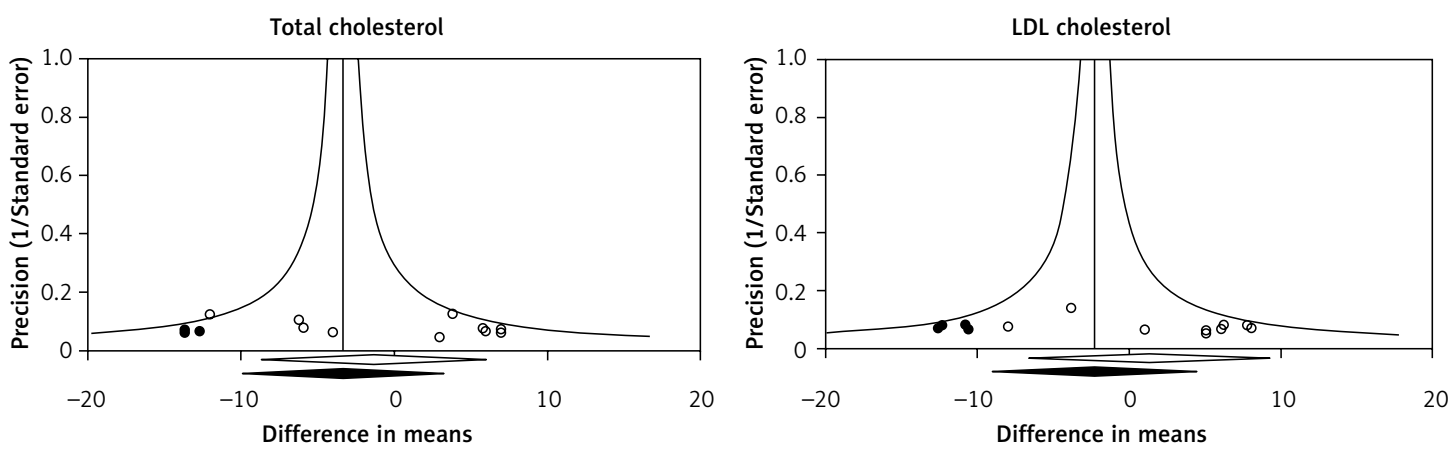

HDL cholesterol
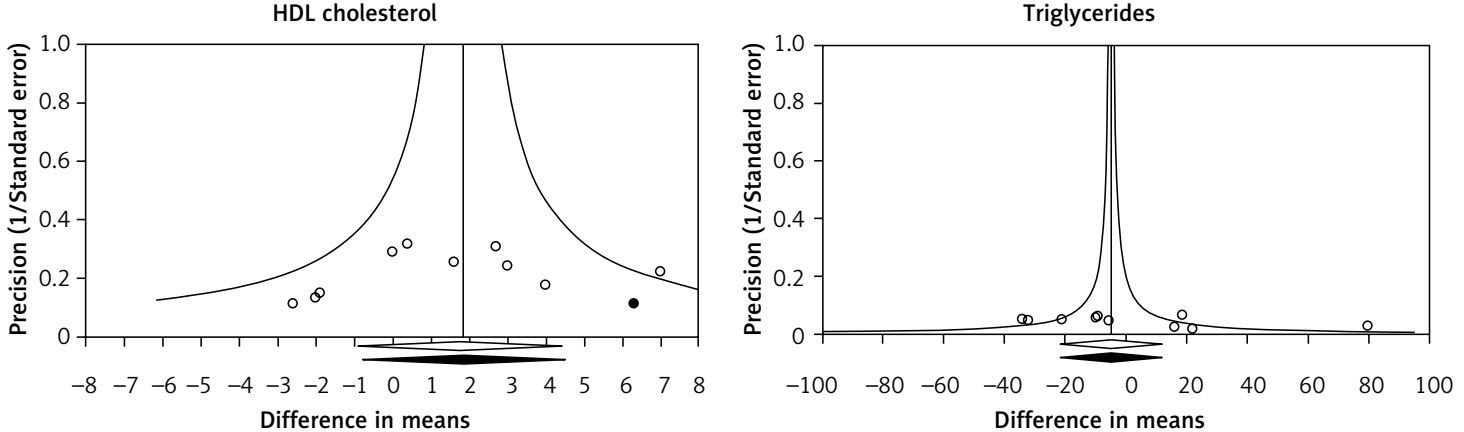

Glucose

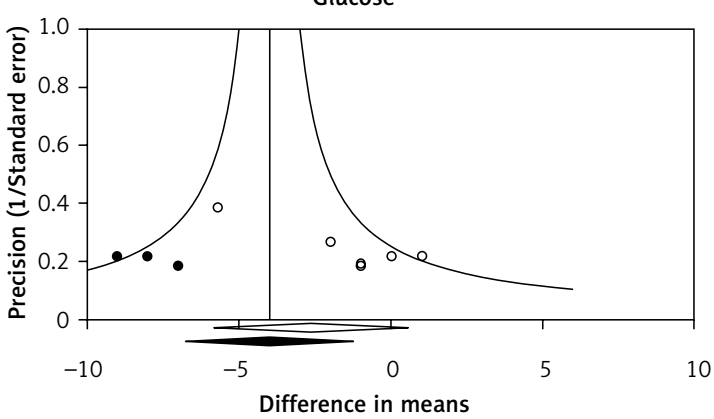

Figure 9. Funnel plots detailing publication bias in the studies selected for analysis. Trim and fill method was used to impute for potentially missing studies. Open circles represent observed published studies; closed circles represent imputed unpublished studies

Table II. Assessment of publication bias in the impact of astaxanthin supplementation on plasma lipids and glucose concentrations

\begin{tabular}{|c|c|c|c|c|c|c|c|c|}
\hline \multirow[t]{2}{*}{ Parameter } & \multicolumn{3}{|c|}{ Begg's rank correlation test } & \multicolumn{5}{|c|}{ Egger's linear regression test } \\
\hline & $\begin{array}{c}\text { Kendall's } \\
\operatorname{Ta}^{a}\end{array}$ & z-value & $p$-value ${ }^{b}$ & Intercept & $95 \% \mathrm{Cl}$ & $t$ & $\mathrm{~d} f$ & $p$-value ${ }^{b}$ \\
\hline Total cholesterol & 0.04 & 0.18 & 0.86 & 0.89 & $\begin{array}{c}-0.62 \text { to } \\
2.39\end{array}$ & 1.36 & 8 & 0.21 \\
\hline LDL-C & -0.03 & 0.10 & 0.92 & 0.94 & $\begin{array}{c}-0.19 \text { to } \\
2.08\end{array}$ & 1.96 & 7 & 0.09 \\
\hline HDL-C & 0.00 & 0.00 & 1.00 & -0.37 & $\begin{array}{c}-1.80 \text { to } \\
1.06\end{array}$ & 0.60 & 8 & 0.57 \\
\hline Triglycerides & 0.18 & 0.72 & 0.47 & 1.41 & $\begin{array}{c}-1.67 \text { to } \\
4.48\end{array}$ & 1.06 & 8 & 0.32 \\
\hline Glucose & 0.13 & 0.38 & 0.71 & 2.13 & $\begin{array}{c}0.73 \text { to } \\
3.53\end{array}$ & 4.22 & 4 & 0.01 \\
\hline
\end{tabular}

${ }^{a}$ With continuity correction; ${ }^{b}$ Two-tailed.

transcriptome in lipid-loaded hepatocytes [35]. In diet-induced obesity in mice, ASTX significantly increased the hepatic mRNA expression of antioxidant nuclear factor erythroid-related factor 2 and reduced plasma triacylglycerol (TAG), alanine transaminase (ALT) and aspartate transaminase
(AST) levels [36]. Furthermore, ASTX reduced plaque macrophage infiltration and apoptosis in the atheroma and enhanced plaque stability in hyperlipidemic rabbits. In vivo and in vitro studies have shown that ASTX inhibits the oxidation of $\operatorname{LDL}[37,38]$ and limits the activation of mac- 
rophage activation and the production of proinflammatory cytokines [39]. It was speculated that ASTX generates its hypotriglyceridemic effect by decreasing VLDL TG secretion consecutive to increased fatty acid $\beta$-oxidation in the liver [32]. Indeed, ASTX raises fat consumption in muscle by activating carnitine palmitoyltransferase-1 (CPT-1), thus lowering adiposity in mice.

Antidiabetic effects of ASTX could be explained by means of several mechanisms. In a diabetic $\mathrm{db} / \mathrm{db}$ mice model, ASTX may protect pancreatic $\beta$-cells against glucose toxicity by decreasing blood glucose levels and hyperglycemia-induced oxidative stress and by increasing serum insulin levels [40]. In an experimental model of high fructose-fat diet (HFFD)-fed mice, ASTX enhanced insulin sensitivity by lowering serine phosphorylation of insulin receptor substrates (IRS), raising the association of IRS and phosphatidylinositol 3-kinase ( $\mathrm{PI} 3 \mathrm{~K})$, and raising Akt phosphorylation in the liver, consecutively promoting the hepatic IRS-PI3K-Akt pathway of insulin signaling [41]. Another study showed that ASTX modulates endoplasmic reticulum (ER) stress, reactive oxygen species (ROS) production, phosphorylation of c-Jun-N-terminal kinase 1 (JNK1), reactive oxygen species (ROS) production, and nuclear factor- $\mathrm{B}$-mediated inflammation in the liver of HFFD-fed mice [42]. A recent in vitro study evaluated whether ASTX alleviates cytokine- and free fatty acid-induced insulin resistance. The results obtained showed that ASTX ameliorates insulin resistance by defending cells from oxidative stress developed by different stimuli consisting of TNF- $\alpha$ and palmitate [43]. Furthermore, ASTX may be able to prevent the progression of diabetic nephropathy by reducing glomerular mesangial area and by decreasing hyperglycemia and oxidative stress [44].

The presence of dietary fat influences the magnitude of ASTX assimilation in the small intestine [45]. Furthermore, the bioavailability of ASTX is increased after meals and decreased by about $40 \%$ in smokers [45]. In experimental and human studies, ASTX seems to be well tolerated, and no notable toxicity has been described. It has been shown that persons with an allergy to sea foods may experience hypotension, hypersensitivity reactions, pigmentation of the skin, hypocalcemia, abnormal hair growth or decreased libido after consuming ASTX [46].

In 1987, the US Food and Drug Administration (FDA) authorized ASTX as a feed additive for the aquaculture industry and since 1999 as a dietary supplement [47]. The safety of ASTX extracted from $H$. pluvialis has been confirmed by several toxicological studies, leading to its affirmation as a Generally Recognized as Safe (GRAS) compound by the FDA in 2010. Following a demand from the European Commission, the European Food Safety Authority (EFSA) Panel on Dietetic Products, Nutrition and Allergies (NDA) recommended a maximum intake of $4 \mathrm{mg}$ of ASTX per day [48]. Human clinical trials have utilized oral ASTX in a dose that varies from $4 \mathrm{mg}$ up to $100 \mathrm{mg} /$ day.

This meta-analysis has some limitations. Most significantly, the qualified RCTs generally had modest populations and limited follow-up [54, 55]. Moreover, the studies involved were heterogeneous concerning the population similarities, the concept of the study, and ASTX quantity. Finally, the smoking status, an important determinant of bioavailability of ASTX, could not be considered in this meta-analysis due to lack of data.

In conclusion, this meta-analysis of data from 10 RCT arms did not indicate a significant effect of supplementation with ASTX on plasma lipid profile, but a slight glucose-lowering effect was observed. Further, well-designed trials are necessary to validate these results.

\section{Conflict of interest}

The authors declare no conflict of interest.

This meta-analysis was written independently; no company or institution supported it financially. No professional writer was involved in the preparation of this meta-analysis.

\section{References}

1. Zhao ZW, Cai W, Lin YL, et al. Ameliorative effect of astaxanthin on endothelial dysfunction in streptozotocin-induced diabetes in male rats. Arzneimittel-Forschung 2011; 61: 239-46.

2. Boussiba S, Cohen Z, Richmond A, Vonshak A. Procedure for large-scale production of astaxanthin from Haematococcus. Google Patents 2000.

3. Choi HD, Kang HE, Yang SH, Lee MG, Shin WG. Pharmacokinetics and first-pass metabolism of astaxanthin in rats. Br J Nutrition 2011; 105: 220-7.

4. Aoi W, Naito Y, Takanami Y, et al. Astaxanthin improves muscle lipid metabolism in exercise via inhibitory effect of oxidative CPT I modification. Biochem Biophys Res Comm 2008; 366: 892-7.

5. Derosa G, Limas CP, Macías PC, Estrella A, Maffioli P. Dietary and nutraceutical approach to type 2 diabetes. Arch Med Sci 2014; 10: 336.

6. Kavitha K, Kowshik J, Kishore TK, Baba AB, Nagini S. Astaxanthin inhibits NF-kappaB and Wnt/beta-catenin signaling pathways via inactivation of Erk/MAPK and PI3K/ Akt to induce intrinsic apoptosis in a hamster model of oral cancer. Biochim Biophys Acta 2013; 1830: 4433-44.

7. Kowshik J, Baba AB, Giri H, et al. Astaxanthin inhibits JAK/STAT-3 signaling to abrogate cell proliferation, invasion and angiogenesis in a hamster model of oral cancer. PLoS One 2014; 9: e109114.

8. Palozza P, Torelli C, Boninsegna A, et al. Growth-inhibitory effects of the astaxanthin-rich alga Haematococcus pluvialis in human colon cancer cells. Cancer Lett 2009; 283: 108-17. 
9. Choi HD, Youn YK, Shin WG. Positive effects of astaxanthin on lipid profiles and oxidative stress in overweight subjects. Plant Foods Hum Nutrition 2011; 66: 363-9.

10. Wolf AM, Asoh S, Hiranuma $\mathrm{H}$, et al. Astaxanthin protects mitochondrial redox state and functional integrity against oxidative stress. J Nutr Biochem 2010; 21: 381-9.

11. Sahebkar A, Serban C, Ursoniu S, Banach M. Effect of curcuminoids on oxidative stress: a systematic review and meta-analysis of randomized controlled trials. J Funct Foods 2015; (in press), DOI: 10.1016/j.jff.2015.01.005.

12. Lauver DA, Driscoll EM, Lucchesi BR. Disodium disucci nate astaxanthin prevents carotid artery rethrombosis and ex vivo platelet activation. Pharmacology 2008; 82 67-73.

13. Gross GJ, Lockwood SF. Cardioprotection and myocardial salvage by a disodium disuccinate astaxanthin derivative ( $\langle\mathrm{i}\rangle$ Cardax</i $\rangle^{\mathrm{TM}}$ ). Life Sci 2004; 75: 215-24.

14. Gross GJ, Hazen SL, Lockwood SF. Seven day oral supplementation with Cardax TM (disodium disuccinate astaxanthin) provides significant cardioprotection and reduces oxidative stress in rats. Mol Cell Biochem 2006; 283: 23-30.

15. Hussein G, Nakamura M, Zhao Q, et al. Antihypertensive and neuroprotective effects of astaxanthin in experimental animals. Biol Pharm Bull 2005; 28: 47-52.

16. Hussein G, Goto H, Oda S, Sankawa U, Matsumoto K, Watanabe $H$. Antihypertensive potential and mechanism of action of astaxanthin: III. Antioxidant and histopathological effects in spontaneously hypertensive rats. Biol Pharm Bull 2006; 29: 684-8.

17. Banach M, Serban C, Aronow WS, et al. Lipid, blood pressure and kidney update 2013. Int Urol Nephrol 2014; 46: 947-61.

18. Lee DH, Lee YJ, Kwon KH. Neuroprotective effects of astaxanthin in oxygen-glucose deprivation in SH-SY5Y cells and global cerebral ischemia in rat. J Clin Biochem Nutrition 2010; 47: 121-9.

19. Kristinsson HG, Miyashita K. Marine antioxidants. Polyphenols and carotenoids from algae. In: Antioxidants and Functional Components in Aquatic Foods. Edited by: Hordur G. Kristinsson. John Wiley \& Sons, Ltd. 2014.

20. Valko M, Leibfritz D, Moncol J, Cronin MT, Mazur M, Telser J. Free radicals and antioxidants in normal physiological functions and human disease. Int J Bioch Cell Biol 2007; 39: 44-84.

21. Bohn T. Bioavailability of non-provitamin A carotenoids. Curr Nutr Food Sci 2008; 4: 240-58.

22. McNulty HP, Byun J, Lockwood SF, Jacob RF, Mason RP. Differential effects of carotenoids on lipid peroxidation due to membrane interactions: X-ray diffraction analysis. Biochim Biophys Acta 2007; 1768: 167-74.

23. Jia Y, Kim JY, Jun HJ, et al. The natural carotenoid astax anthin, a PPAR-alpha agonist and PPAR-gamma antagonist, reduces hepatic lipid accumulation by rewiring the transcriptome in lipid-loaded hepatocytes. Mol Nutrition Food Res 2012; 56: 878-88.

24. Liu PH, Aoi W, Takami M, et al. The astaxanthin-induced improvement in lipid metabolism during exercise is mediated by a PGC-1alpha increase in skeletal muscle. J Clin Biochem Nutrition 2014; 54: 86-9.

25. Ikeuchi M, Koyama T, Takahashi J, Yazawa K. Effects of astaxanthin in obese mice fed a high-fat diet. Biosci Biotechnol Biochem 2007; 71: 893-9.

26. Higgins J, Green S. Cochrane handbook for systematic reviews of interventions version 5.0. 2 (updated Sep- tember, 2009). The Cochrane Collaboration, 2009. www cochrane-handbook org/(accessed 18 May 2009). 2010.

27. Borenstein M, Hedges L, Higgins J, Rothstein H. Comprehensive meta-analysis version 2. Englewood, NJ: Biostat 2005; 104.

28. Sahebkar A. Does PPARgamma2 gene Pro12Ala polymorphism affect nonalcoholic fatty liver disease risk? Evidence from a meta-analysis. DNA Cell Biol 2013; 32: 188-98.

29. Sahebkar A. Are curcuminoids effective C-reactive protein-lowering agents in clinical practice? Evidence from a meta-analysis. Phytother Res 2014; 28: 633-42.

30. Duval S, Tweedie R. Trim and fill: a simple funnel-plotbased method of testing and adjusting for publication bias in meta-analysis. Biometrics 2000; 56: 455-63.

31. Karppi J, Rissanen TH, Nyyssönen K, et al. Effects of astaxanthin supplementation on lipid peroxidation. Int J Vitam Nutr Res 2007; 77: 3-11.

32. Yang Y, Seo JM, Nguyen A, et al. Astaxanthin-rich extract from the green alga Haematococcus pluvialis lowers plasma lipid concentrations and enhances antioxidant defense in apolipoprotein E knockout mice. J Nutr 2011; 141: 1611-7.

33. Yoshida $\mathrm{H}$, Yanai $\mathrm{H}$, Ito $\mathrm{K}$, et al. Administration of natural astaxanthin increases serum HDL-cholesterol and adiponectin in subjects with mild hyperlipidemia. Atherosclerosis 2010; 209: 520-3.

34. lizuka M, Ayaori M, Uto-Kondo H, et al. Astaxanthin enhances ATP-binding cassette transporter A1/G1 expressions and cholesterol efflux from macrophages. J Nutr Sci Vitaminol 2012; 58: 96-104.

35. Jia Y, Kim JY, Jun HJ, et al. The natural carotenoid astaxanthin, a PPAR- $\alpha$ agonist and PPAR-gamma antagonist, reduces hepatic lipid accumulation by rewiring the transcriptome in lipid-loaded hepatocytes. Mol Nutr Food Res 2012; 56: 878-88.

36. Yang Y, Pham TX, Wegner CJ, et al. Astaxanthin lowers plasma TAG concentrations and increases hepatic antioxidant gene expression in diet-induced obesity mice. Br J Nutr 2014; 112: 1797-804.

37. Jacobsson LS, Yuan XM, Ziedén B, Olsson AG. Effects of alpha-tocopherol and astaxanthin on LDL oxidation and atherosclerosis in WHHL rabbits. Atherosclerosis 2004; 173: 231-7.

38. Iwamoto T, Hosoda K, Hirano R, et al. Inhibition of low-density lipoprotein oxidation by astaxanthin. J Atheroscler Thromb 1999; 7: 216-22.

39. Kishimoto $\mathrm{Y}$, Tani M, Uto-Kondo $\mathrm{H}$, et al. Astaxanthin suppresses scavenger receptor expression and matrix metalloproteinase activity in macrophages. Eur J Nutr 2010; 49: 119-26

40. Uchiyama K, Naito Y, Hasegawa G, Nakamura N, Takahashi J, Yoshikawa T. Astaxanthin protects beta-cells against glucose toxicity in diabetic $\mathrm{db} / \mathrm{db}$ mice. Redox Rep 2002; 7: 290-3.

41. Bhuvaneswari S, Anuradha CV. Astaxanthin prevents loss of insulin signaling and improves glucose metabolism in liver of insulin resistant mice. Can J Physiol Pharmacol 2012; 90: 1544-52.

42. Bhuvaneswari S, Yogalakshmi B, Sreeja S, Anuradha CV. Astaxanthin reduces hepatic endoplasmic reticulum stress and nuclear factor-kappaB-mediated inflammation in high fructose and high fat diet-fed mice. Cell Stress and Chaperones 2014; 19: 183-91.

43. Ishiki M, Nishida $Y$, Ishibashi $H$, et al. Impact of divergent effects of astaxanthin on insulin signaling in 16 cells. Endocrinology 2013; 154: 2600-12. 
44. Naito Y, Uchiyama K, Aoi W, et al. Prevention of diabetic nephropathy by treatment with astaxanthin in diabetic $\mathrm{db} / \mathrm{db}$ mice. Biofactors 2004; 20: 49-59.

45. Okada Y, Ishikura M, Maoka T. Bioavailability of astaxanthin in Haematococcus algal extract: the effects of timing of diet and smoking habits. Biosci Biotechnol Biochem 2009; 73: 1928-32.

46. Comhaire F, Garem YE, Mahmoud A, Eertmans F, Schoonjans F. Combined conventional/antioxidant "Astaxanthin" treatment for male infertility: a double blind, randomized trial. Asian J Androl 2005; 7: 257-62.

47. Guerin M, Huntley ME, Olaizola M. Haematococcus astaxanthin: applications for human health and nutrition. Trends Biotechnol 2003; 21: 210-6.

48. Tetens I. EFSA NDA Panel (EFSA Panel on Dietetic Products, Nutrition and Allergies), 2014. Scientific Opinion on the safety of astaxanthin-rich ingredients (AstaREAL A1010 and AstaREAL L10) as novel food ingredients. Europen Food Safety Authority, 2014.

49. Baralic I, Djordjevic B, Dikic N, et al. Effect of astaxanthin supplementation on paraoxonase 1 activities and oxidative stress status in young soccer players. Phytother Res 2013; 27: 1536-42.

50. Karppi J, Rissanen TH, Nyyssonen K, et al. Effects of astaxanthin supplementation on lipid peroxidation. Int J Vitam Nutr Res 2007; 77: 3-11.

51. MacDermid JC, Vincent JI, Gan BS, Grewal R. A blinded placebo-controlled randomized trial on the use of astaxanthin as an adjunct to splinting in the treatment of carpal tunnel syndrome. Hand 2012; 7: 1-9.

52. Nakagawa K, Kiko T, Miyazawa T, et al. Antioxidant effect of astaxanthin on phospholipid peroxidation in human erythrocytes. Br J Nutr 2011; 105: 1563-71.

53. Saito M, Yoshida K, Saito W, et al. Astaxanthin increases choroidal blood flow velocity. Graefes Arch Clin Exp Ophthalmol 2012; 250: 239-45.

54. Serban C, Sahebkar A, Antal D, Ursoniu S, Banach M. Effects of supplementation with green tea catechins on plasma C-reactive protein concentrations: a systematic review and meta-analysis of randomized controlled trials. Nutrition 2015; DOI: 10.1016/j.nut.2015.02.004

55. Banach M, Aronow WS, Serban C, et al. Lipids, blood pressure and kidney update 2014. Pharmacol Res 2015; 95-96C: 111-25. 